\title{
Detection of Zika virus in Brazilian patients during the first five days of infection - urine versus plasma
}

R Pessôa ${ }^{1}$, JV Patriota ${ }^{2}$, MdL de Souza ${ }^{2}$, A Abd El Wahed ${ }^{3}$, SS Sanabani ${ }^{1}$

1. Department of Pathology, Hospital das Clínicas, School of Medicine, University of São Paulo, São Paulo, Brazil

2. Municipal Hospital of Tuparetama, Pernambuco, Brazil

3. Division of Microbiology and Animal Hygiene, Georg-August-University, Goettingen, Germany

Correspondence: Sabri Saeed Sanabani (sabyem_63@yahoo.com)

Advantages of testing for Zika virus (ZIKV) in urine have been reported, such as the persistence of ZIKV in this type of specimen for up to 20 days after ZIKV disease onset. We investigate 61 patients in the first 5 days post-symptom onset and find more patients testing positive for ZIKV in plasma samples $(n=46)$, than in corresponding urine samples $(n=37)$. For patients respectively testing positive in both plasma and urine $(n=28)$, respective viral loads appeared similar.

Results of recent studies have suggested that after Zika virus (ZIKV) disease onset, the virus persists at higher levels and for a longer period in urine (up to ca 20 days) than in serum (up to ca 5 days) $[1,2]$. To provide further data, we tested for the presence of ZIKV in the urine and corresponding plasma specimens of 61 patients presenting symptoms of ZIKV disease in Brazil. The samples were collected between 1 and 5 days after symptom onset. During this phase of infection, the proportion of patients testing positive in plasma samples (46/61) appeared to be higher than those testing positive in urine samples (37/61).

\section{Laboratory investigations}

Urine and corresponding plasma samples (i.e. from the same patient at the same date) that had been previously collected during the large outbreak in Tuparetama, Brazil, in 2015, were retrospectively analysed in this study. All samples had been obtained within the first 5 days of onset of symptoms, from a total of 61 individuals, who had been diagnosed as having ZIKV disease on clinical and epidemiological grounds. The main symptoms reported for the patients were rash $(n=47)$, fever $\geq 38.5^{\circ} \mathrm{C}(n=42)$, headache $(n=40)$, joint pain $(n=39)$, and conjunctivitis $(n=37)$. The median age of patients was 35 years (range: $1-80$ years), with the majority being female $(n=41)$. No patient was coinfected with another flavivirus such as dengue at the time of the sample collection, although previous infection with dengue was not known. None of the women were pregnant.

Specimens were investigated by real-time reverse-transcription polymerase chain reaction (RT-PCR), with a published primer set (FP: $5^{\circ}$-GAAGCCCTTGGATTCTTGAACGAGG-3' and RP: $5^{\prime}$-CGACTCATCTCTTCTAGGACATATCC-3") [3] and a fluorescein (FAM)/black hole quencher 1 (BHQ1)labelled Taqman probe, targeting the non-structural protein (NS) 5 genetic region of ZIKV (ZIKAp 5'-FAMGGGAGAGAGAACTCAGGAGGTGG-BHQ1-3'). A sample was considered positive for ZIKV when the mean cycle threshold $(C t)$ value obtained from three parallel realtime RT-PCRs was $\leq 40$ cycles.

\section{Zika virus RNA in urine and plasma}

Among the 61 patients, more tested positive for ZIKV RNA in plasma $(n=46)$ than in urine $(n=37)$ within the 5 days post-symptom onset, although the difference was not statistically significant $(p=0.12$; two-tailed test) (Table).

In 28 cases, ZIKV RNA was detected in both types of samples. Ct values from plasma and urine samples collected at the same time post-symptom onset did not seem to differ (Figure).

\section{Background and discussion}

ZIKV belongs to the genus Flavivirus, a group of RNA viruses transmitted by arthropods. The virus name originates from the Zika Forest of Uganda, where it was first isolated in 1947 from an infected rhesus monkey [4]. In 2007, ZIKV caused an outbreak in Yap State, Micronesia [5]. The outbreak was characterised by relatively mild disease including symptoms such as rash, arthralgia, and conjunctivitis, which are commonly observed upon ZIKV infection $[5,6]$. Seven years later, the virus appeared in French Polynesia and larger 


\section{FIGURE}

Comparison between the cycle threshold $(C t)$ values of plasma and corresponding urine samples from Zika virus infected patients testing positive for both types of samples in the first five days post-symptom onset, Brazil, 2015 $(\mathrm{n}=28$ patients)

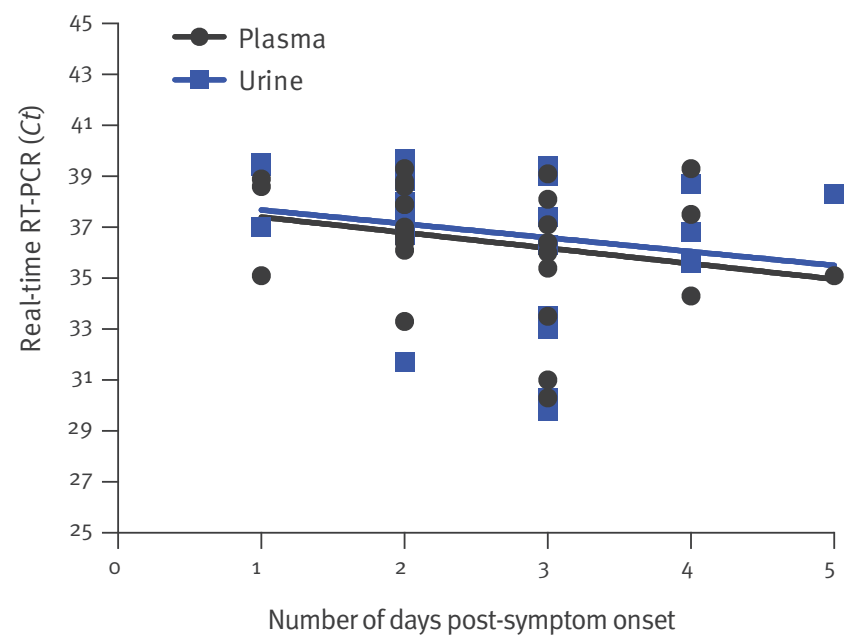

RT-PCR: reverse transcription-polymerase chain reaction; ZIKV: Zika virus.

A linear regression analysis was performed by plotting the $\mathrm{Ct}$ values of plasma and urine samples versus the time post onset of symptoms using PRISM (Graphpad SoJware Inc., San Diego, California). The Ct values of ZIKV RNA in plasma and urine samples appear similar.

outbreaks were reported in New Caledonia, the Cook Islands, and Easter Island, whereby coincident with the French Polynesia ZIKV outbreak, an increased incidence of neurological complications was observed [7]. The first cases of ZIKV infection in the Americas were detected in Brazil in May 2015 [3,6,8] and, since, the virus spread to other countries in North and South America [9]. In Brazil, concurrent with ZIKV infections, neurological complications were also reported, as well as congenital malformations including microcephaly [10].

Due to cross-reactivity between members of the Flavivirus genus, the serological diagnostic of ZIKV is difficult [11]. Although there are molecular tests based on virus isolation and/or detection of ZIKV RNA during the acute phase of infection, the low-level and short period of viraemia remains a challenge [3]. Recently, Gourinat et al [1] observed that ZIKV RNA in six patients from French Polynesia was detectable at higher levels and for longer periods after symptom onset in urine samples (up to ca 20 days) than in corresponding serum samples (up to ca 5 days). The larger time window postdisease onset of possible ZIKV detection in urine was confirmed by others who investigated returning travellers to the United States (US) [2]. It was further noted that among 55 persons with urine and serum samples obtained within the first 5 days of symptom onset, a higher proportion tested positive for ZIKV RNA in urine
TABLE 1A

Real-time reverse transcription-polymerase chain reaction results of screening plasma and corresponding urine samples from patients in Brazil, 2015 ( $\mathrm{n}=61$ patients)

\begin{tabular}{|l|l|l|l|l|}
\hline Sample ID & Sex & Age & Ct plasma & Ct urine \\
\hline
\end{tabular}
1 day post-symptom onset

\begin{tabular}{|l|c|c|c|c|}
\hline 64 & F & 5 & 38.6 & 37.0 \\
\hline 60 & M & 15 & Neg & 39.3 \\
\hline 77 & M & 46 & 38.9 & 39.4 \\
\hline 30 & F & 26 & 35.1 & 39.5 \\
\hline
\end{tabular}

2 days post-symptom onset

\begin{tabular}{|c|c|c|c|c|}
\hline 74 & $\mathrm{~F}$ & 50 & $\mathrm{Neg}$ & 31.5 \\
\hline 18 & $\mathrm{~F}$ & 16 & 36.6 & 31.7 \\
\hline 70 & $\mathrm{~F}$ & 50 & Neg & 32.0 \\
\hline 46 & $\mathrm{~F}$ & 31 & Neg & 34.7 \\
\hline 61 & $\mathrm{~F}$ & 44 & 36.1 & 36.7 \\
\hline 51 & $\mathrm{~F}$ & 45 & 37.9 & 36.9 \\
\hline 20 & $\mathrm{~F}$ & 10 & 33.3 & 37.0 \\
\hline 40 & $\mathrm{~F}$ & 4 & 38.6 & 37.1 \\
\hline 53 & $\mathrm{~F}$ & 19 & 39.3 & 37.1 \\
\hline 67 & $\mathrm{~F}$ & 37 & 38.8 & 37.6 \\
\hline 31 & $\mathrm{~F}$ & 20 & 36.8 & 38.0 \\
\hline 58 & $M$ & 46 & Neg & 38.5 \\
\hline 32 & $\mathrm{~F}$ & 33 & 37.0 & 38.8 \\
\hline 11 & $\mathrm{~F}$ & 44 & 37.9 & 38.8 \\
\hline 22 & $M$ & 8 & 36.4 & 39.1 \\
\hline 16 & $\mathrm{~F}$ & 39 & 36.7 & 39.7 \\
\hline 57 & $\mathrm{~F}$ & 1 & 26.2 & Neg \\
\hline 2 & $M$ & 37 & 36.6 & $\mathrm{Neg}$ \\
\hline 62 & $\mathrm{~F}$ & 45 & 39.2 & Neg \\
\hline 65 & $M$ & 45 & $\mathrm{Neg}$ & $\mathrm{Neg}$ \\
\hline 75 & $\mathrm{~F}$ & 10 & Neg & Neg \\
\hline 73 & $\mathrm{~F}$ & 36 & $\mathrm{Neg}$ & $\mathrm{Neg}$ \\
\hline
\end{tabular}

3 days post-symptom onset

\begin{tabular}{|l|c|c|c|c|}
\hline 39 & $\mathrm{~F}$ & 8 & 39.1 & 29.8 \\
\hline 23 & $\mathrm{~F}$ & 80 & 37.1 & 30.3 \\
\hline 19 & $\mathrm{M}$ & 28 & 36.0 & 33.0 \\
\hline 43 & $\mathrm{~F}$ & 55 & 38.1 & 33.5 \\
\hline 44 & $\mathrm{~F}$ & 35 & $\mathrm{Neg}$ & 35.2 \\
\hline 34 & $\mathrm{~F}$ & 40 & $\mathrm{Neg}$ & 36.1 \\
\hline 69 & $\mathrm{~F}$ & 38 & 31.0 & 36.3 \\
\hline 21 & $\mathrm{M}$ & 42 & 36.4 & 37.4 \\
\hline 28 & $\mathrm{~F}$ & 39 & 35.4 & 39.0 \\
\hline 54 & $\mathrm{M}$ & 48 & 30.3 & 39.2 \\
\hline 29 & $\mathrm{M}$ & 28 & 33.5 & 39.4 \\
\hline 9 & $\mathrm{~F}$ & 56 & 34.1 & Neg \\
\hline 13 & $\mathrm{M}$ & 5 & 35.1 & Neg \\
\hline 55 & $\mathrm{~F}$ & 10 & 37.4 & Neg \\
\hline 63 & $\mathrm{~F}$ & 34 & 37.5 & Neg \\
\hline 76 & M & 9 & 38.8 & Neg \\
\hline 71 & F & 62 & 38.9 & Neg \\
\hline
\end{tabular}

$C t$ : cycle threshold; F: female; ID: identity; M: male; Neg: negative.

The $C t$ value is the mean of the three $C t$ s of each sample. 
TABLE 1B

Real-time reverse transcription-polymerase chain reaction results of screening plasma and corresponding urine samples from patients in Brazil, 2015 ( $\mathrm{n}=61$ patients)

\begin{tabular}{|l|l|l|l|l|l|}
\hline Sample ID & Sex & Age & \multicolumn{2}{l|}{ Ct plasma } & Ct urine \\
\hline 4 days post-symptom onset & M & 65 & Neg & 35.0 \\
\hline 35 & F & 31 & 37.5 & 35.6 \\
\hline 7 & F & 70 & 39.3 & 36.8 \\
\hline 50 & F & 46 & 34.3 & 38.7 \\
\hline 27 & F & 18 & Neg & 39.3 \\
\hline 47 & F & 43 & 34.4 & Neg \\
\hline 15 & F & 28 & 36.5 & Neg \\
\hline 5 & F & 73 & 36.6 & Neg \\
\hline 17 & M & 34 & 37.3 & Neg \\
\hline 10 & M & 11 & 37.4 & Neg \\
\hline 24 & F & 15 & Neg & Neg \\
\hline 37 & M & 13 & Neg & Neg \\
\hline 56 & F & \multicolumn{5}{l|}{} \\
\hline 5 days post-symptom onset & F & 27 & 35.1 & 38.3 \\
\hline 33 & M & 42 & 33.6 & Neg \\
\hline 1 & M & 3 & 37.0 & Neg \\
\hline 4 & M & 49 & 37.2 & Neg \\
\hline 14 & M & 8 & 37.6 & Neg \\
\hline 6 & F & 36 & Neg & Neg \\
\hline 8 & & &
\end{tabular}

$C t$ : cycle threshold; F: female; ID: identity; M: male; Neg: negative.

The $C t$ value is the mean of the three $C t$ s of each sample.

than in serum [2]. The findings opened the door for the use of urine for the diagnosis of ZIKV infection [1].

In our study, we focused on the detection of ZIKV in samples from 61 patients collected within the first 5 days of symptom onset. In contrast to the two previous studies mentioned above $[1,2]$, patients in our study had an overall a higher ZIKV detection rate in plasma than in urine during active infection. Moreover, our data do not support the recent finding of higher level of ZIKV RNA in urine than in serum during the acute phase of the disease [1]. The reasons for this discrepancy remain unclear, although this might have been due to the small number of patients investigated in all three studies. Another hypothesis could be that host immune and genetic factors might affect the viral load of ZIKV in distinct body fluids, whereby this may vary among individuals. A similar suggestion has been reported in cases of infection with dengue virus, another flavivirus [12]. In this respect, patients in our study were Brazilian citizens, while the two other studies investigated patients from French Polynesia and travellers returning to the US. Previous infection with other flaviviruses might also alter and/or enhance the replication of ZIKV in specific organs [13]. Information about past dengue infection was however not available for our patients. Finally, beside the small sample size, one limitation of our study was the cross-sectional design that only permitted obtaining data at single time points.

In conclusion, we recommend the simultaneous testing of blood and urine samples in ZIKV infected individuals with focus on plasma samples in the first 5 days of infection. Further investigations will be required to more fully determine factors influencing ZIKV pathogenesis.

\section{Acknowledgements}

This work was partially supported by grants 2014/24596-2 from the Fundação de Amparo à Pesquisa do Estado de São Paulo. The funders had no role in design of the study, data collection and analysis, decision to publish, or preparation of the manuscript. We would like to acknowledge our colleague Shereen Petersen, DPZ, for English proofreading of the manuscript.

\section{Conflict of interest}

None declared.

\section{Authors' contributions}

Conceived and designed the experiments: RP, AAEW, SSS. Performed the experiments: RP, JVP, MLS, AAEW, SSS. Data analysis: RP, JVP, MLS, AAEW, SSS. Drafted the manuscript: AAEW, SSS. Critical revision: RP, JVP, MLS. All authors read and approved the final manuscript.

\section{References}

1. Gourinat AC, O'Connor O, Calvez E, Goarant C, DupontRouzeyrol M. Detection of Zika virus in urine.Emerg Infect Dis. 2015;21(1):84-6. DOI: 10.3201/eid2101.140894 PMID: 25530324

2. Bingham AM, Cone M, Mock V, Heberlein-Larson L, Stanek D, Blackmore C, et al. Comparison of Test Results for Zika Virus RNA in Urine, Serum, and Saliva Specimens from Persons with Travel-Associated Zika Virus Disease - Florida, 2016. MMWR Morb Mortal Wkly Rep. 2016;65(18):475-8. DOI: 10.15585/ mmwr.mm6518e2 PMID: 27171533

3. Pessôa R, Patriota JV, Lourdes de Souza M, Felix AC, Mamede $\mathrm{N}$, Sanabani SS. Investigation Into an Outbreak of Dengue-like Illness in Pernambuco, Brazil, Revealed a Cocirculation of Zika, Chikungunya, and Dengue Virus Type 1.Medicine (Baltimore). 2016;95(12):e3201. DOI: 10.1097/MD.0000000000003201 PMID: 27015222

4. Kirya BG. A yellow fever epizootic in Zika forest, Uganda, during 1972: Part 1: Virus isolation and sentinel monkeys. Trans R Soc Trop Med Hyg. 1977;71(3):254-60. DOI: 10.1016/00359203(77)90020-7 PMID: 407675

5. Duffy MR, Chen TH, Hancock WT, Powers AM, Kool JL, Lanciotti RS, et al. Zika virus outbreak on Yap Island, Federated States of Micronesia. N Engl J Med. 2009;360(24):2536-43. DOI: 10.1056/NEJMoa0805715 PMID: 19516034

6. Campos GS, Bandeira AC, Sardi SI. Zika Virus Outbreak, Bahia, Brazil.Emerg Infect Dis. 2015;21(10):1885-6. DOI: 10.3201/ eid2110.150847 PMID: 26401719

7. Roth A, Mercier A, Lepers C, Hoy D, Duituturaga S, Benyon $\mathrm{E}$, et al. Concurrent outbreaks of dengue, chikungunya and Zika virus infections - an unprecedented epidemic wave of mosquito-borne viruses in the Pacific 2012-2014. Euro Surveill. 2014;19(41):20929. DOI: 10.2807/1560-7917. ES2014.19.41.20929 PMID: 25345518

8. Cardoso CW, Paploski IA, Kikuti M, Rodrigues MS, Silva MM, Campos GS, et al. Outbreak of Exanthematous Illness Associated with Zika, Chikungunya, and Dengue Viruses, Salvador, Brazil. Emerg Infect Dis. 2015;21(12):2274-6. DOI: 10.3201/eid2112.151167 PMID: 26584464 
9. Centers for Disease Control and Prevention (CDC). Travel notices. Zika Virus. Atlanta: CDC. [Accessed Jan 26 2016]. Available from: http://wwwnc.cdc.gov/travel/notices

10. Paixão ES, Barreto F, da Glória Teixeira MG, da Conceição N. Costa M, Rodrigues LC. History, Epidemiology, and Clinical Manifestations of Zika: A Systematic Review.Am J Public Health. 2016;106(4):606-12. DOI: 10.2105/AJPH.2016.303112 PMID: 26959260

11. Musso D, Gubler DJ. Zika Virus.Clin Microbiol Rev. 2016;29(3):487-524. DOI: 10.1128/CMR.00072-15 PMID: 27029595

12. Lan NT, Hirayama K. Host genetic susceptibility to severe dengue infection.Trop Med Health. 2011;39(4Suppl);73-81. DOI: 10.2149/tmh.2011-So8 PMID: 22500139

13. Dejnirattisai W, Supasa P, Wongwiwat W, Rouvinski A, BarbaSpaeth G, Duangchinda T, et al. Dengue virus sero-crossreactivity drives antibody-dependent enhancement of infection with zika virus. Nat Immunol. 2016: Epub ahead of print. DOI: 10.1038/ni.3515 PMID: 27339099

\section{License and copyright}

This is an open-access article distributed under the terms of the Creative Commons Attribution (CC BY 4.0) Licence. You may share and adapt the material, but must give appropriate credit to the source, provide a link to the licence, and indicate if changes were made.

This article is copyright of the authors, 2016. 